\title{
IMPLEMENTASI PROGRAM WAKAF DI UNIT CABANG ACT DURI
}

\author{
Mukhlis \\ STAI Hubbul Wathan Duri \\ Jl. Karya Desa Balaimakam Duri \\ mukhlis@staihubbulwathan.ac.id
}

\author{
Abdi Sahrial Harahap \\ Universitas Pembangunan Panca Budi \\ Jl. Jendral Gatot Subroto Sikambing Medan \\ afifo_yasmine@yahoo.com
}

DOI: 10.46781/al-mutharahah.v17i2.155

\begin{abstract}
The existence of ACT in Duri, Bengkalis Regency, is a global humanitarian organization based on voluntarism. In implementing the institution, there are several waqf programs, including renovation of houses of worship and drilled clean water wells for the needs of and helping the poor in the Duri area. This research was conducted with a descriptive approach, namely, interview, observation, interview, and referring to journals related to this research. In this case, it becomes the research subject: Implementation of the Waqf Program while being the object of research at the ACT Duri Branch Unit. The presence of ACT Duri Branch provides a new phenomenon in accommodating the hopes of the community in issuing their assets in the form of waqf, both cash waqf, assets, land, livestock, businesses that have enormous beneficial value for the welfare of the ummah. The programs promoted by ACT Duri Branch focused on renovating houses of worship and drilling wells. The bore well program is implemented to address the educational needs of the pesantren children and the pesantren's surrounding communities who are in dire need given that the clean water conditions in Duri are very uneven and where clean water is located. In this condition, ACT Duri is taking steps to make drilling wells the flagship waqf program in the Duri area.
\end{abstract}

Keywords: ACT Duri, Implementation of Waqf

\begin{abstract}
Abstrak
Keberadaan ACT di Duri Kabupaten Bengkalis merupakan sebuah lembaga kemanusiaan global dan berbasis kerelawaan kermawanan, dalam mengimplemantasikan kelembagaan ada beberapa program wakaf antara lain renovasi rumah ibadah dan sumur bor air bersih untuk keperluan dan membantu masyarakat miskin di daerah Duri. Penelitian ini dilakukan penelitian dengan pendekatan deskriptif yaitu, interview observasi wawancara dan merujuk kepada jurnal-jurnal yang berkaitan dengan penelitian ini. Dalam hal ini menjadi subjek penelitian: Implementasi Program Wakaf sedangkan menjadi objek penelitian di Unit Cabang ACT Duri. Kehadiran ACT Cabang Duri memberikan fenomena baru dalam mengakomodir harapan masyarakat dalam memgeluarkan hartanya dalam bentuk wakaf, baik wakaf tunai, harta, tanah, ternak, usaha yang memiliki nilai manfaat yang begitu besar untuk kesejahteraan ummat. Program-program yang digalakkan oleh ACT Cabang Duri tertumpu kepada renovasi rumah ibadah dan sumur bor. Program sumur bor dilaksanakan pada kebutuhan pendidikan anak pesantren dan masyarakat persekitaran pesantren tersebut yang sangat membutuhkan mengingat bahwa kondisi air bersih di Duri sangat langkah dan tidak merata tempat -temapat lokasi air bersihnya. Kondisi seperti ini ACT Duri mengambil langkah untuk membuat sumur bor sebagai program wakaf unggulan di wilayah Duri.
\end{abstract}




\section{Kata Kunci: ACT Duri, Implementasi Wakaf}

\section{A. PENDAhuluan}

Satu yang mengarahkan perlu dirawat dan kembangkan di alam pikir para pengelola wakaf adalah perlunya inovasi baru tanpa henti di tengah perkembangan zaman. Para pengelola wakaf dengan bantuan segenap pihak yang bersangkutan, sedia dan semestinya, harus menjadi motor penggerak kemajuan dan pengembangan ekonomi kerakyatan. Apalagi bila kita melihat ekonomi kerakyatan yang diampu atau dikelola oleh negara, dalam bentuk koperasi misalnya, belum berjalan secara maksimal dan bahkan relatif "jalan" di tempat. Wakaf sangat perlu dikembangkan ke arah wakaf produktif, sebagaimana yang digalakkan oleh Badan Wakaf Indonesia (BWI), agar pembangunan umat dapat terbantu. ${ }^{1}$

Kesejahteraan manusia bisa diwujudkan jika kebutuhan atau keperluan manusia yang berupa sandang, pangan, perumahan, dan kesehatan bisa terpenuhi. Namun tidak semua manusia mampu memenuhi kebutuhan hidup mereka tanpa bantuan orang lain yang disebabkan kurangnya akses dan tidak adanya kesempatan untuk mendapatkan pekerjaan yang layak untuk kehidupannya. Hal ini yang menjadi penyebab semangat dan dorongan praktik perilaku membantu orang lain yang saat ini dikenal sebagai filantropi sosial. ${ }^{2}$

Jika kita cermati lebih jauh, ditemukan bukti-bukti empirik bahwa bertambahnya jumlah penduduk yang di bawah garis kemiskinan bukanlah karena persoalan kekayaan alam yang tidak sebanding dengan jumlah penduduk (over population) akan tetapi lain persoalan distribusi yang kurang merata serta rendahnya rasa kesetiakawanan diantara sesama anggota masyarakat. Lingkaran arah kemiskinan yang terbentuk dalam masyarakat kita lebih banyak dalam bentuk kemiskinan structural sehingga upaya untuk mengatasinya harus dilakukan melalui upaya yang bersifat prinsipil, sistematis dan konprenhensif, bukan hanya bersifat parsial dan sporadis dan sesaat saja. Untuk mewujudkan kesejahteraan secara menyeluruh (universal), bukanlah sesuatu yang mudah dikerjakan, karena kesejahteraan materiil maupun spiritual hanya mungkin dapat dicapai beberapa kondisi yang ada, diantaranya dengan melaksanakan beberapa asas (esensi) yang penting untuk mewujudkan kesejahteraan, yaitu tercapainya hak-hak azasi manusia, termasuk hak mendapatkan keadilan ${ }^{3}$

Fenomena wakaf memberikan sebuah solusi dalam mengatasi persoalan-persoalan masyarakat baik kemiskinan untuk itu ACT Duri merupakan bagian dari melaksanakan dan mengimplementasikan program-progam wakaf serta mengakomadir harta-harta pewakif di Duri untuk menanggulangi kemiskinan dan memberikan serta memberikan kesejahteraan masyarakat berupa pemanfaatan harta yaitu renovasi rumah ibadah dan sumur bor. Kelembagaan ACT Duri merupakan kelembagaan yang hergerak dalam berbagai sosial masyarakat yang membantu kompenen-omponen masyarakat dengan cepat.

Kajian ini sangat penting dilakukan diteliti karena gerak cepat dan mengimplementasi harta pewakif diamanahkan kepada lembaga ACT Duri, yang merupakan lembaga yang melaksanakan dan mengaplikasikan program-program wakafnya dengan terarah (kredibel) transfaran dan akuntabel di masyarakat. Kajian ini sangat berbeda dengan kajian sebelumnya dalam mengimplemntasikan program-program wakaf.

\section{Hakikat Implementasi}

Secara etimologi, pengertian implementasi menurut kamus Webster yang dikutip oleh Sholichin Wahab adalah penerapan berasal dari Bahasa Inggris yaitu to implement berarti to

${ }^{1}$ Dr. Amelia Fauzia, dkk, Fenomena Wakaf di Indonesia :Tantangan Menuju Wakaf Produktif, Penerbit : BWI , 2018, hlm. 3-4

2 Aris Puji Purwatiningsih, Muchlis Yahya, Literature Review Filantropi Islam antara Tahun 2008 hingga 2018, Jurnal Al-Muzara'ah Vol. 6 No. 2. 2018, hlm. 129

3 Kamarullah, M. H.I \& Ratnawati, M. Ag, Kontrobusi Wakaf Tanah mili Sebagai Potensi Ekonomi Umat (Studi Kasus Di Desa Menemeng)Jurnal El-Huda Volume 11 Nomer 1/2020 hlm.76 
improvide the means for carrying out (menyediakan sarana untuk melakukan sesuatu ); dan to give practical effect to (untuk menimbulkan dampak atau akibat terhadap sesuatu). Teori implementasi menurut Edward, Emerson, Grindle serta Mize menjelaskan bahwa terdapat empat variabel kritis dalam implementasi kebijakan public atau program diantaranya, komunikasi atau kejelasan informasi, konsistensi informasi (communications), ketersediaan sumberdaya dalam jumlah dan mutu tertentu (resources), sikap dan komitmen dari pelaksana program atau kebijakan para birokrat (disposition), dan struktural birokrasi atau standar operasional yang mengatur tata kerja dan tata laksana (bureaucratic strucuture). ${ }^{4}$

\section{Konsep Dasar Wakaf}

Secara historis, wakaf yang merupakan sektor nirlaba, telah memainkan peran penting dalam penyediaan layanan sosial, seperti pendidikan, rumah sakit, dan fasilitas umum, seperti jalan, masjid, jembatan, merawat anak yatim, orang miskin, yang membutuhkan, para janda, orang cacat, tua,dan sebagainya. Dalam bahasa Arab, wakaf berarti: pemotongan, pencegahan, ketenangan, atau keheningan. Sebagai istilah teknis, itu adalah properti apa pun yang prosesnya dikhususkan, asalkan ada, terhadap layanan sosial tertentu yang dipilih untuk tujuan tertentu. ${ }^{5}$

a. Pengertian ini banyak mempengaruhi para mujtahid-mujtahid dalam menetapkan pengertian wakaf. Seperti di bawah ini: wakaf menurut Abu Hanifah dan sebagian ulama Hanafiyah: adalah menahan benda yang statusnya tetap milik waqif (orang yang mewakafkan hartanya), sedangkan yang disedekahkan adalah manfaatnya benda tersebut.

b. Wakaf menurut Malikiyah: adalah menjadikan manfaat benda yang dimiliki, baik berupa sewa atau hasilnya untuk diserahkan kepada orang yang berhak menerimanya, dengan penyerahan berjangka waktu, sesuai dengan kehendak pewaqif.

c. Wakaf menurut Shafi'iyah: adalah menahan harta yang dapat diambil manfatnya disertai dengan kekalan zat benda, lepas dari penguasaan waqif dan dimanfaatkan pada sesuatu yang diperbolehkan oleh agama.

d. Wakaf menurut Hanabilah: adalah menahan kebebasan bagi pemilik harta dalam membelanjakan hartanya yang bermanfaat disertai dengan kekekalan zat benda serta memutus semua hak wewenang atas benda itu, sedangkan manfaatnya dipergunakan dalam hal kebajikan untuk mendekatkan diri kepada Allah.

e. Wakaf menurut Undang-Undang nomor 41 tahun 2004 adalah: perbuatan hukum waqif untuk memisahkan dan/atau menyerahkan sebagian harta benda miliknya untuk dimanfaatkan selamanya atau untuk jangka waktu tertentu sesuai dengan kepentingan guna keperluan ibadah dan/atau kesejahteraan umum menurut shari'at.

f. Wakaf menurut PP nomor 28 tahun 1977 adalah: perbuatan hukum seseorang atau badan hukum yang menisahkan sebagian dari harta kekayaannya yang berupa tanah milik dan melembagakannya untuk selama-lamanya bagi kepentingan peribadatan atau keperluan umum lainnya sesuai dengan ajaran Islam.

g. Wakaf menurut Kompilasi Hukum Islam: adalah perbuatan hukum seseorang atau kelompok orang atau badan hukum yang memisahkan sebagian dari benda

\footnotetext{
${ }^{4}$ Mukhlis, Implementasi Zakat Pada Lembaga Amil Zakat Ibadurrahman, Al-Masharif:Jurnal Ilmu Ekonomi dan KeIslaman Volume 7, Nomor 2 Juli-Desember 2019, hlm. 277

${ }^{5}$ Dergisi, Proposal Framework of Waqf Institutions' Governance and Its Economic and Social Implications, International, Journal Of Islamic Economic and Finance Studies (IJIEF) Vol:4, Jilid :2 Juli 2018, hlm. 7
} 
miliknya dan melembagakannya untuk selama-lamanya guna kepentingan ibadah atau keperluan umum lainnya sesuai dengan ajaran Islam.

\section{Jenis-Jenis Wakaf}

Macam-macam Wakaf Bila ditinjau dari segi peruntukan ditujukan kepada siapa wakaf itu, maka wakaf dapat dibagi menjadi dua (2) macam:

a. Wakaf Ahli yaitu, wakaf yang ditujukan kepada orang-orang tertentu, seorang atau lebih, keluarga si wakif atau bukan. Wakaf seperti ini juga disebut wakaf Dzurri. Apabila ada seseorang mewakafkan sebidang tanah kepada anaknya, lalu kepada cucunya, wakafnya sah dan yang berhak mengambil manfaatnya adalah mereka yang ditunjuk dalam pernyataan wakaf. Wakaf jenis ini (wakaf ahli/dzurri) kadang-kadang juga disebut wakaf 'alal aulad, yaitu wakaf yang diperuntukkan bagi kepentingan dan jaminan sosial dalam lingkungan keluarga (famili), lingkungan kerabat sendiri ${ }^{6}$.

b. Wakaf Khairi yaitu, wakaf yang secara tegas untuk kepentingan agama (keagamaan) atau kemasyarakatan (kebajikan umum). Seperti wakaf yang diserahkan untuk keperluan pembangunan masjid, sekolah, jembatan, rumah sakit, panti asuhan anak yatim dan lain sebagainya. Dalil mengenai wakaf secara lebih detail terdapat dalam hadis. Terdapat banyak hadis yang menjelaskan disyariatkannya wakaf, diantaranya kisah yang diriwayatkan Ibn 'Umar, bahwa 'Umar Ibn Khathab memperoleh tanah (kebun) di Khaibar, lalu ia datang kepada Nabi SAW, seraya berkata, "Wahai Rasulullah saya memperoleh tanah yang belum pernah saya peroleh harta yang lebih baik bagiku melebihi tanah tersebut, maka apa yang engkau perintahkan (kepadaku) mengenainya?" Nabi SAW menjawab,"Jika mau, kamu tahan pokoknya dan kamu sedekahkan (hasilnya)". Ibnu 'Umar berkata, "Maka 'Umar menyedekahkan tanah tersebut (dengan mensyaratkan) bahwa tanah itu tidak dijual, tidak dihibahkan, dan tidak diwariskan, yaitu kepada orang-orang fakir, kerabat, riqab (hamba sahaya), sabilillah, tamu dan ibn sabil. Tidak berdosa bagi orang yang mengelola untuk memakan dari (hasil) tanah itu secara ma'ruf (wajar) atau memberi makan seorang teman, dengan tanpa menjadikannya sebagai harta hak milik pribadi. ${ }^{7}$

Wakaf juga boleh digunakan bersama elemen Islam lain seperti zakat untuk tujuan pemanfaatan seperti untuk program pendidikan. Negara-negara Barat seperti Amerika Serikat dan Great Britain (Inggris) sudah menjalankan dan membangunkan serta memaksimalkan aplikasi wakaf dalam bentuk endowment secara urusan muamalah dalam kehidupan mereka. Ternyata, ia dapat memberi keuntungan dan kemudahan terbaik dalam segenap lapangan kerja untuk kesejahteraan hidup rakyatnya ${ }^{8}$

Murat Çizakça menyatakan amalan saleh yang bersifat kekal dalam Islam dikenal sebagai wakaf. Menurut Monzer Kahf, wakaf adalah satu perbuatan memegang harta tertentu dan memelihara untuk memberi faedah ke pada masyarakat Islam. Syahnaz Sulaiman dan Aznan Hasan menyatakan, pada asasnya wakaf dan endowment merupakan dua entiti filantropi yang mempunyai ciri-ciri yang hampir sama yaitu pemberian yang berterusan dan hanya manfaatnya saja yang didistribusikan kepada benefisiari yang tertentu. Perbedaan di antara wakaf dan endowment datang dari segi yang paling asas iaitu tasawur dan konsep kepemilikan. $^{9}$

${ }^{6}$ Kementerian Agama Republik Indonesia , Fiqh Wakaf, Direktorat Jenderal Bimbingan Masyarakat Islam Direktorat Pemberdayaan Wakaf 2006 hlm. 15

${ }^{7}$ Nurodin Usman, Pengelolaan Wakaf Produktif dalam Bentuk SPBU Studi Kasus SPBU Masjid Agung Semarang, Jurnal Muqtasi Volume 4 Nomor 1, Juni 2013 hlm. 149-150.

${ }^{8}$ Mohamad Zaim Ismail dkk, Pemerkasaan Wakaf di Malaysia :Satu Sorotan Labuan e-Journal of Muamalat and Society, Vol. 9, 2015 hlm. 10

${ }^{9}$ Mutiara Dwi Sari Dkk, Waqf-Entrepreneurship Synergy at University College Bestari, Jurnal Syariah, Jil. 26, Bil. 1 (2018) hlm. 46 


\section{Pengembangan Wakaf Global ACT Profile ACT}

Didirikan pada 21 April 2005 sebagai lembaga kemanusian global berbasis kerelawaan dan kedermawanan dengan visi besar mewujudkan peradaban yang lebih baik memperluas lingkup program dengan lini (Global Qurban, Global Zakat, dan Global Wakaf) Adapun pengembangan terhadap wakaf yang dilakukan oleh ACT antara lain:

\section{Wakaf Pangan}

Wakaf Air solusi atas kebutuhan air bersih masyarakat yang dalam kesulitan. Mengaktivasi sumber air baru di wilayah kekeringan dengan mencari titik potensi sumber mata air, melalui pembangunan sumur, irigasi, bendungan, dan infrastruktur air bersih.

Wakaf sawah merupakan konsep jaminan pangan masyarakat melalui pengelolaan wakaf dalam bentuk lahan pertanian untuk produksi pangan dengan sistem multimanfaat, sehingga dapat menghasilkan pangan baik dan berkualitas. Wakaf pangan dan makanan dengan terkumpul dana sebanyak: Rp.1.687.933.909 (Satu milyar enam ratus delapan puluh tujuh juta sembilan ratus tiga puluh tiga ribu sembilan ratus Sembilan rupiah)

\section{Wakaf Pendidikan}

Ilmu yang bermanfaat mengalir bagi anak-anak bangsa dari keluarga tidak mampu dan kurang upaya, wakaf akan di wujudkan dalam berbagai sarana pendidikan melalui perbaikan dan pembangunan sekolah $\mathrm{m}$ serta prasarana lainnya dilokasi-lokasi yang membutuhkan adapun dana terkumpul sebesar: Rp. 81.533.400 (Delapan puluh satu juta lima ratus tiga puluh tiga ribu empat ratus rupiah)

\section{Wakaf Kesehatan}

Wakaf alat-alat kesehatan memiliki implementasi berupa sarana mobil ambulance beserta obat-obatan untuk mendukung dan menyokonng rumah sakit dan klinik dalam pelayanan medis bagi korban konflik kemanusiaan Suriah dan Pelastina.

\section{Wakaf Ekonomi}

Wakaf ternak menggerakkan dan menjalankan perekonomian lewat lumbung perternakan masyarakat. Indukan ternak qurban yang diwakafkan akan di pelihara dan dikembangbiakkan serta terus dimanfaatkan demi kemashlahatan umat. Wakaf infrastruktur didedikasikan untuk memenuhi kebutuhan infrastruktur yang sangat dibutuhkan dan diperlukan oleh masyarakat. Wakaf ritel merupakan hasil optimalisasi dana wakaf melalui pengelolaan bisnis, sehingga lebih produktif terus berkelanjutan dan memberi manfaat berlipat bagi umat. Wakaf Properti di tujukan untuk meningkatkan manfaat dari asset wakaf agar mampu berkontribusi di bidang social ekonomi serta menopang kemajuan pembangunan satu daerah. Wakaf Surat berharga adalah wakaf yang diambil dari persentase perolehan diveden selama surat berharga tersebut dimiliki oleh wakif. Dividen dari jumlah saham yang diwakafkan akan dioptimalkan manfatnya melalui global wakaf dengan berbagai program kemanusian (sesuai peruntukkannya: pangan, pendidikan, kesehatan, ekonomi dan lain-lain). Dalam hal ini saham tetap di kelola oleh pemilik saham atau perusahaan yang bersangkutan. Adapun dana terkumpul Rp. 64,803.480 (Enam puluh empat juta delapan ratus tiga ribu emapat ratus delapn puluh rupiah $)^{10}$

Peranan ACT sangat posititif dalam pergerakan kemanusia, ACT tersebesar di seluruh Indonesia bahkan ACT telah berbuat sampai kemancanegara yang terkena bencana baik 
bencana alam maupun bencana peperang dan kelaparan di belahan dunia. Fenomena ini telah memberikan sebuah wacana pergerakkan social di tingkat antar bangsa-bangsa dunia.

Keberadaan ACT tidak diragukan lagi dalam pemberdayaan dan pengelolaan dana umat. Untuk Kabupaten Bengkalis Kota Duri ACT berdiri pada tanggal 18 Desember 2018. Kehadiran ACT di Kabupaten Bengkalis memberikan sebuah langkah-langkah positif dalam mengerakkan filantropi di tengah-tengah masyarakat di Negeri junjungan Kabupaten Bengkalis, yang mempunyai potensi sumberdaya alam yang luar biasa.

Hal yang demikian pengelolaan dan pengembangan wakaf di ACT Duri sangat praktis bahwa ACT Duri menerbitkan beberapa program wakaf di sampaikan kepada para pewakif Duri untuk dapat mewakafkan hartanya boleh di pergunakan untuk membantu masyarakat miskin. Program-program tersebut dilaksanakan dan penerapan di tengah-tengah masyarakat, sehingga pengumpulan dana wakaf dapat terorganisir dengan baik dari para pewakif bisa dilihat secara jelas program-program ACT Duri yang dijalankan sesuai dengan koridor agama dan harapan para pewakif. Kehadiran ACT Cabang Duri, memberikan sebuah harapan baru di tengah masyarakat Islam di Duri Kecamatan Mandau-Bengkalis dalam mengatasi permsalahan-permasalahan social yang di hadapi oleh masyarakat miskin dalam kehidupan sehari-harinya. ACT Cabang Duri-Bengkalis terletak di Jalan Sudirman merupakan lembaga yang memiliki tingkat kepedulian dan hadir di tengah krisis menimpa masyarakat pada masa saat sekarang ini terlebih masa pandemi covid 19.

\section{B. METODE PENELITIAN}

Pendekatan Penelitian (research approach) merupakan rencana dan prosedur penelitian yang meliputi langkah-langkah dari asumsi-asumsi luas hingga metode-metode terperinci dalam pengumpulan analisa dan interprestasi data. ${ }^{11}$ Penelitian ini dilakukan penelitian dengan pendekatan deskriptif yaitu, interview observasi wawancara dan merujuk kepada jurnal-jurnal yang berkaitan dengan penelitian ini. Dalam hal ini menjadi subjek penelitian: Implementasi Program Wakaf sedangkan menjadi objek penelitian di Unit Cabang ACT Duri. Adapun menjadi sumber data:

1. Kantor Unit Cabang ACT (Aksi Cepat Tanggap) Duri

2. Buku dan jurnal-jurnal dan karya ilmiah yang berkaitan dengan permasalahan wakaf. Untuk mendapatkan berbagai sumber informasi yang benar diperlukan adanya data yang asli sehingga mampu mengungkap permasalahan yang diteliti. Dalam penelitian pengumpulan teknik yang digunakan data premier dengan teknik interview dan observasi. ${ }^{12}$

\section{PEMBAHASAN}

Wakaf secara khusus dapat membantu kegiatan masyarakat umum sebagai bentuk kepedulian terhadap ummat, dan regenerasi yang akan datang. Kegiatan dan kepedulian sosial seperti ini telah dianjurkan dalam syariat Islam sebagai kebutuhan manusia, bukan saja terbatas pada kaum muslimin, tetapi juga bagi masyarakat non-muslim. Perspektif Islam terhadap praktik wakaf sosial seperti ini telah lama berlangsung sepanjang sejarah Islam, bahkan bentuk dan tujuannya sangat berkembang pesat. Maka wajar kalau jumlah wakaf Islam banyak sekali dan menyebar di seluruh negara-negara berpenduduk mayoritas muslim yang dapat memacu angka pertumbuhan ekonomi. ${ }^{13}$ Di tengah permasalahan sosial masyarakat Indonesia dan tuntutan akan kesejahteraan ekonomi pada saat ini, keberadaan lembaga wakaf menjadi sangat penting dan juga strategis. Di samping sebagai salah satu

\footnotetext{
${ }^{11}$ Jhon W.Cresswel, Research Design (Pendekatan metode Kualitatif, Kuantitaif dan Campuran) Penerbit Pustaka Pelajar 2018, cet. III hlm. 3

${ }^{12}$ Mukhlis, op.cit. 282

${ }^{13}$ Abdul Hakim, Manajemen Harta Wakaf Produktif dan Investasi Dalam Sistem Ekonomi Syari'ah Jurnal , Riptek, Vol.4, No.I1, Tahun 2010 hlm. 23
} 
aspek ajaran Islam yang berdimensi spiritual, wakaf juga merupakan ajaran yang menekankan pentingnya kesejahteraan ekonomi (dimensi sosial). Oleh karenanya, pendefinisian ulang terhadap wakaf agar memiliki makna yang lebih relevan dengan kondisi riil persoalan kesejahteraan itu sangat penting dilakukan dan dilaksanakan secara tepat.

Lembaga-lembaga di atas telah banyak membuat program untuk mewujudkan keadilan sosial yang dihasilkan dari investasi dana wakaf yang dihimpun dari masyarakat untuk masyarakat, seperti pembentukan rumah sakit, sekolah, dan kampung peternakan yang berpotensi mengembangkan wakaf dalam bentuk uang untuk membangun kesejahteraan masyarakat secara luas dan berkesinambungan secara terus menerus. Program-program yang telah dicanangkan oleh lembaga wakaf di Indonesia dengan mengelola dana wakaf dalam bentuk uang ini adalah dalam upaya agar harta wakaf lebih berkembang manfaat bernilai ekonomi dan sosialnya. Contohnya saja, penghimpunan dan pengelolaan dana wakaf uang pada Tabung Wakaf Indonesia yang hasil pengelolaannya disalurkan pada bidang pendidikan, ekonomi, dan bidang sosial. Selain itu, hasil pengelolaan yang di peroleh oleh Badan Wakaf Indonesia disalurkan pada bidang pendidikan dan kesehatan dan ekonomi. Dari pemaparan di atas, terlihat bahwa sudah banyak lembaga-lembaga wakaf di Indonesia yang mencoba untuk mengelola wakaf uang secara produktif yang sesuai dengan peraturan maupun perundangundangan tentang wakaf. Implemntasi Program wakaf yang dilakukan oleh ACT Duri melalui wawancara dengan pimpinan ACT Duri (Muhammad Zaki Mubarak) ${ }^{14}$ menjelaskan bahwa potensi wakaf Duri sangat memberikan dorongan positif untuk membentu masyarakat golong miskin. Semenjak berdirinya ACT Duri pada Tahun 2018 langkah-langkah yang dilakukan mesosialisasikan program wakaf yang dilaksanakan oleh ACT Duri berupa penggalangan dana wakaf berupa, Renovasi masjid, dan Sumur Bor. Pembuatan sumur bor bagi pesantren melihat dari kondisinya bahwa wilayah duri merupakan wilayah minyak sehingga menimbulkan kelangkaan air bersih disebabkan telah bercampur air dengan minyak. Kelangkaan air bersih merupakan hal yang serius untuk kehidupan manusia, apalagi di lingkungan pesantren. Selanjutnya Renovasi Masjid Al-Ilham di wilayah Suku Sakai yang merupakan suku asli yang berdomisili di daerah pinggiran kota Duri. Dilihat dari kehidupan mereka sangat layak dan pantas untuk dibantu melalui dana wakaf yang telah di kumpulkan oleh ACT Duri melalui para pewakif yang ada di sekitar kota Duri. Unuk mengetahui semenjak berdirinya ACT Duri bisa terlihat dari data penerimaan dana pewakif semenjak ACT Duri dari tahun $2018-2020 .^{15}$

${ }^{14}$ Muhammad Zaki Mubarak. Kepala Unit Cabang ACT Duri wawancara pada tanggal 23 Nopember 2020 pukul $11.00 \mathrm{Wib}$

${ }^{15}$ Data Penerimaan Dana Pewakif kepada Pihak ACT Duri pada tanggal 23 Nopember 2020 
Al-Mutharahah: Jurnal Penelitian dan Kajian Sosial Keagamaan

Vol. 17 No. 2. Juli-Desember 2020

Tabel. 1. Data Pewakif ACT Duri

Data Pewakif Per - Tahun ACT Duri

\begin{tabular}{|c|l|c|c|c|c|}
\hline No & Bulan & $\mathbf{2 0 1 8}$ & $\mathbf{2 0 1 9}$ & $\mathbf{2 0 2 0}$ & Jumlah \\
\hline $\mathbf{1}$ & Januari & 0 & 4 & 7 & 11 \\
\hline $\mathbf{2}$ & Februari & 0 & 4 & 7 & 11 \\
\hline $\mathbf{3}$ & Maret & 0 & 2 & 5 & 7 \\
\hline $\mathbf{4}$ & April & 0 & 0 & 2 & 2 \\
\hline $\mathbf{5}$ & Mei & 0 & 2 & 32 & 34 \\
\hline $\mathbf{6}$ & Juni & 0 & 0 & 34 & 34 \\
\hline $\mathbf{7}$ & Juli & 0 & 4 & 13 & 17 \\
\hline $\mathbf{8}$ & Agustus & 0 & 6 & 31 & 37 \\
\hline $\mathbf{9}$ & September & 0 & 2 & 25 & 27 \\
\hline $\mathbf{1 0}$ & Oktober & 0 & 6 & 32 & 38 \\
\hline $\mathbf{1 1}$ & November & 0 & 2 & 12 & 14 \\
\hline $\mathbf{1 2}$ & Desember & 0 & 5 & & 5 \\
\hline & & Total & & & $\mathbf{2 3 7}$ \\
\hline
\end{tabular}

Dari tabel di atas menunjukan bahwa awal pendirian ACT Duri tahun 2018 belum ada pewakif namun berjalannya waktu pada tahun 2019 dan tahun 2020 menunjukkan angka yang signifikan dari para pewakif di kota Duri.

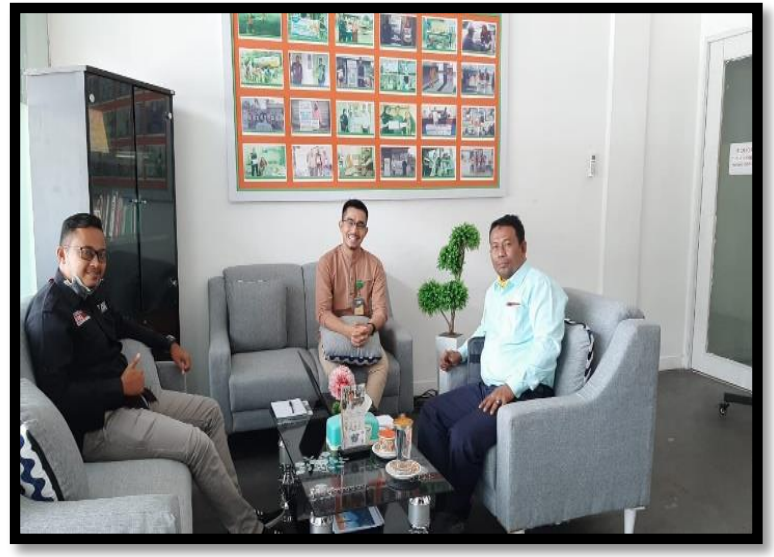

Gambar. 1 Wawancara Dengan Ketua Unit Cabang ACT Duri pada Pukul 11. 00 Wib di Jalan Sudiman Duri tanggal 23 Nopember 2020

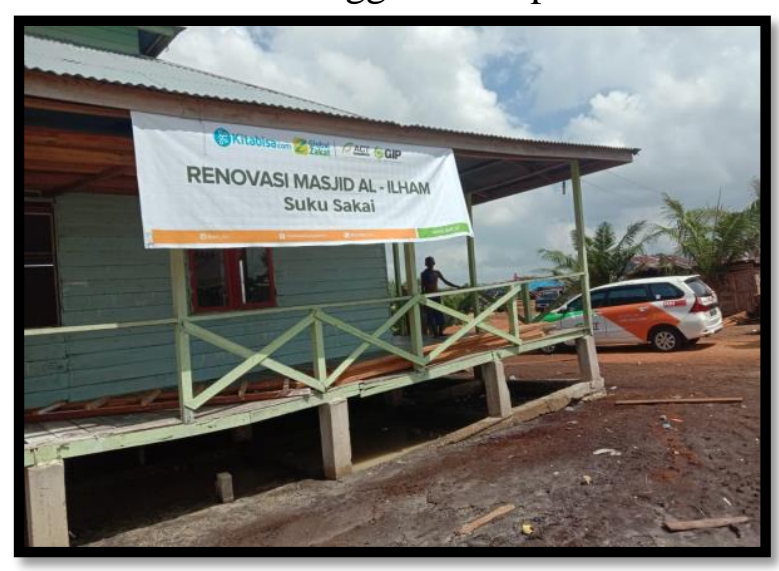

Gambar 2. Wakaf Renovasi Masjid Al-Ilham Alamat: Jl. Jurong KM 12 Jembatan 2 Kecamatan Bathin Solapan 


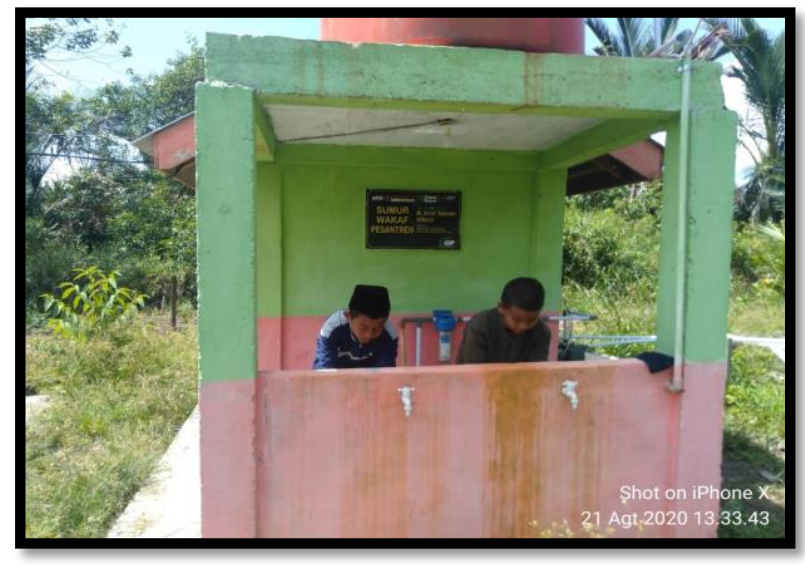

Gambar 3. Sumur Wakaf Pesantren Daarul Fikri, Banglash, Meranti (Sudah selesai dan sudah digunakan)

\section{SIMPULAN}

ACT Cabang Duri bergerak dalam mengembangkan serta membuat program-program kesejahteraan untuk umat, program-program ACT Duri tidak hanya kepada pendidikan dan kesehetan tetapi masih banyak lagi program-program untuk keumatan sehingga lembagalambaga social lainya dapat berkoloborasi dengan ACT Duri.

Lembaga ACT (Aksi Cepat Tanggap) Duri telah melakukan beberapa programprogram wakaf untuk mewujudkan kemerataan dan keadilan sosial di tengah masyarakat. Program-program tersebut telah memberikan hasil yang baik dalam pengelolaan harta wakaf tersebut. Progran wakaf berupa menginvestasi dana wakaf yang terhimpun dari pewakif, seperti pembangunan rumah sakit, sekolah, dan kampung peternakan yang berpotensi mengembangkan wakaf uang untuk membangun kesejahteraan masyarakat secara luas dan berkesinambungan secara merata.

Program-program yang telah dicanangkan oleh lembaga wakaf di Indonesia dengan mengelola dana wakaf uang dalam bentuk ini adalah dalam upaya agar harta wakaf lebih berkembang manfaat ekonomi dan sosialnya. Contohnya saja, penghimpunan dan pengelolaan dana wakaf uang pada Tabung Wakaf Indonesia yang hasil pengelolaannya disalurkan pada bidang pendidikan, ekonomi, dan bidang social lainnya. Selain itu, hasil pengelolaan yang di peroleh oleh Badan Wakaf Indonesia disalurkan pada bidang pendidikan dan kesehatan. ${ }^{16}$

\section{DAFTAR PUSTAKA}

Amelia Fauzia, dkk, Fenomena Wakaf di Indonesia: Tantangan Menuju Wakaf Produktif, Penerbit: BWI, 2018.

Aris Puji Purwatiningsih, Muchlis Yahya, Literature Review Filantropi Islam antara Tahun 2008 hingga 2018, Jurnal Al-Muzara'ah Vol. 6 No. 2, 2018.

Nurodin Usman, Pengelolaan Wakaf Produktif dalam Bentuk SPBU Studi Kasus SPBU Masjid Agung Semarang, Jurnal Muqtasi Volume 4 Nomor 1 Juni, 2013.

Mukhlis, Implementasi Zakat Pada Lembaga Amil Zakat Ibadurrahman, Al-Masharif: Jurnal Ilmu Ekonomi dan KeIslaman Volume 7 Nomor 2 Juli-Desember, 2019.

Dergisi, Proposal Framework of Waqf Institutions' Governance and Its Economic and Social Implications, International, Journal Of Islamic Economic and Finance Studies (IJIEF) Vol:4, Jilid: 2 Juli 2018.

Kementerian Agama Republik Indonesia, Fiqh Wakaf, Direktorat Jenderal Bimbingan Masyarakat Islam Dierektorat Pemberdayaan Wakaf, 2006.

${ }^{16}$ Fahmi Medias, Wakaf Produktif Dalam Perspektif Ekonomi Islam, Jurnal La_Riba Volume IV No. 1, 2010 hlm. 77 
Al-Mutharahah: Jurnal Penelitian dan Kajian Sosial Keagamaan

Vol. 17 No. 2. Juli-Desember 2020

Mohamad Zaim Ismail dkk, Pemrakarsa Wakaf di Malaysia: Satu Sorotan Labuan e-Journal of Muamalat and Society, Vol. 9, 2015.

Mutiara Dwi Sari Dkk, Waqf-Entrepreneurship Synergy at University College Bestari, Jurnal Syariah, Jil. 26, Bil. 1, 2018.

Abdul Hakim, Manajemen Harta Wakaf Produktif dan Investasi Dalam Sistem Ekonomi Syari'ah Jurnal Riptek, Vol.4, No.I1, 2010.

Fahmi Medias, Wakaf Produktif Dalam Perspektif Ekonomi Islam, Jurnal La_Riba Volume IV N0:1, 2010.

Kamarullah \& Ratnawati, Kontrobusi Wakaf Tanah mili Sebagai Potensi Ekonomi Umat (Studi Kasus Di Desa Menemeng) Jurnal El-Huda Volume 11 No.1, 2020.

https://www.globalwakaf.com/id/wakaf

Muhammad Zaki Mubarak. Kepala Unit Cabang ACT Duri wawancara pada tanggal 23 Nopember 2020 pukul 11.00 WIB 